\title{
Phenobarbital and Cerebral Blood Flow during Hypotension in Newborn Pigs ${ }^{1}$
}

\author{
YUSHIRO YAMASHITA, JAN GODDARD-FINEGOLD, CHARLES F. CONTANT, \\ CHRISTOPHER G. MARTIN, AND LLOYD H. MICHAEL \\ Departments of Pediatrics [Y.Y., J.G.-F., C.G.M.], Pathology [J.G.-F.], Physiology [L.H.M.], Medicine [L.H.M.], \\ Neurosurgery [C.F.C] (Biometrics [C.F.C.]), Divisions of Pediatric Neurology [Y.Y., J.G.-F.] and Neonatology \\ [C.G.M.]; Baylor College of Medicine, the Cain Foundation Laboratories of the Texas Children's Hospital, and \\ the DeBakey Heart Center of the Methodist Hospital, Houston, Texas 077030
}

\begin{abstract}
Phenobarbital sodium ( $\mathrm{PhS}$ ) has been used in anticonvulsant concentrations in premature newborns in attempts to prevent peri- and intraventricular hemorrhages (PIVH). Its effectiveness in preventing PIVH in clinical situations is still uncertain; however, $\mathrm{PhS}$ has reduced PIVH after hypertension in newborn beagles, and it has lowered cerebral blood flow (CBF) during hypertension in newborn beagles and piglets. We hypothesized that $\mathrm{PhS}$ might reduce $\mathrm{CBF}$ during systemic hypotension. Twelve control and $12 \mathrm{PhS}$-treated piglets ( 1 to $2 \mathrm{~d}$ old) were used for microsphere determinations of CBF during 1) steady state; 2) $\mathbf{3 0} \mathrm{min}$ after $\mathrm{PhS}$ (treatment group) or saline infusion (controls); and 3 and 4) during two levels of graded hypotension. Mean arterial blood pressure (MABP) was $61 \pm 13(\mathrm{SD}) \mathrm{mm} \mathrm{Hg}$ (controls) and $57 \pm 13$ (SD) $\mathrm{mm} \mathrm{Hg}$ $(\mathrm{PhS})$ during steady state. Thirty min after the $\mathrm{PhS}$ or saline infusion, MABP and CBF remained unchanged in both groups. CBF during hypotension at MABP of $41 \pm 5$ (SD) $\mathrm{mm} \mathrm{Hg}$ was significantly higher in controls than was $\mathrm{CBF}$ at MABP of $39 \pm 6$ (SD) $\mathrm{mm} \mathrm{Hg}$ in the PhS-treated group ( $p=0.044)$; CBF in the two groups during the second hypotensive phase was not significantly different. However, LOWESS regression suggested that the CBF from the controls dropped as the arterial pressure decreased to less than $37 \mathrm{~mm} \mathrm{Hg}$, whereas $\mathrm{PhS}$ treatment lowered CBF during hemorrhagic hypotension compared with controls at blood pressures greater than $37 \mathrm{~mm} \mathrm{Hg}$ but did not lower CBF further at lower systemic blood pressures. This suggests that $\mathrm{PhS}$ would not, by itself, cause ischemia at blood pressures near the lower limit of autoregulation. (Pediatr Res 33: 598-602, 1993)
\end{abstract}

\section{Abbreviations}

CBF, cerebral blood flow

MABP, mean arterial blood pressure

PhS, phenobarbital sodium

PIVH, periventricular and intraventricular hemorrhage

SS, steady state

PG, prostaglandin

Received May 27, 1992; accepted February 1, 1993.

Correspondence: Jan Goddard-Finegold, M.D., Department of Pediatrics, Baylor College of Medicine, One Baylor Plaza, Houston, TX 77030.

Supported by RO1 NS28388 (J.G.-F.), the Departments of Pediatrics and Pathology, the Section of Pediatric Neurology, and the DeBakey Heart Center Baylor College of Medicine. Facilities are part of the Cain Foundation Laboratories of the Texas Children's Hospital. In addition, our laboratory is part of the Baylor College of Medicine, Mental Retardation Research Center, 5P30-HD24064.

Presented in part at the Twentieth Annual Meeting of the Child Neurology Society, Portland, OR, October 4, 1991.
LOWESS, locally weighted regression and smoothing scatter plots

TX , thromboxane

Some clinical studies have reported that the incidence and/or severity of PIVH in preterm infants decreases when anticonvulsant dosages of $\mathrm{PhS}$ are given either antenatally or early in the postnatal period $(1-5)$. Other studies have questioned the effectiveness of $\mathrm{PhS}$ in preventing PIVH (6-10). It has been shown that $\mathrm{PhS}$ in anticonvulsant concentrations lowers CBF during hypertension in newborn beagles and pigs, which may explain its protective effect against PIVH $(11,12)$. In addition, the incidence of PIVH in PhS-treated newborn beagles after hypertensive insult has been reduced (13). Because of the frequency with which newborns are subjected to hypotensive stress and the question of whether the blood flow-lowering effect of $\mathrm{PhS}$ might potentiate cerebral oligemia or ischemia, we determined the effects of $\mathrm{PhS}$ upon $\mathrm{CBF}$ during graded hemorrhagic hypotension in the newborn piglet.

\section{MATERIALS AND METHODS}

Approval for this study was obtained from the Baylor College of Medicine Animal Care and Use Committee (NIH Assurance no. A3823-01). One- to 2-d-old cross-bred newborn piglets were obtained from a local breeder. Twelve animals served as controls, and 12 animals were $\mathrm{PhS}$-treated.

Surgical procedures were performed under local Xylocaine (Astra Pharmaceutical Products, Inc., Westborough, MA) and i.v. $\alpha$-chloralose $(50 \mathrm{mg} / \mathrm{kg}$ ) anesthesia (Alpha-Chloralose, Sigma Chemical Co., St. Louis, MO) after Ketamine (Ketaset, Aveco Co., Fort Dodge, IA: $200 \mathrm{mg}$ ) and Xylazine (Anased, Lloyd Laboratories, Shenandoah, IA, $20 \mathrm{mg}$ ) were given in combination intramuscularly $(0.5 \mathrm{~mL} / \mathrm{kg})$. Body temperature was monitored by rectal probe and was kept at 38 to $39^{\circ} \mathrm{C}$ (normothermia) by heating pad. Polyethylene catheters (Intramedic, Clay Adams, Parsippany, NJ) were placed in the abdominal aorta via the femoral arteries for monitoring arterial blood pressure, for blood sampling, and for obtaining the microsphere reference samples. A catheter was also placed in the left cardiac ventricle via the left carotid artery. Each animal was artificially ventilated by Harvard small-animal respirator (Harvard Apparatus, Millis, MA) after tracheostomy.

CBF was quantitated by the radioactive microsphere method described previously by Goddard-Finegold et al. (11). CBF values were quantitated by the infusion of radioactive microspheres (15$\mu \mathrm{m}$ size) using the radiolabels ${ }^{141} \mathrm{Ce},{ }^{51} \mathrm{Cr},{ }^{103} \mathrm{Ru}$, and ${ }^{95} \mathrm{Nb}$ (Medical Surgical Division, 3M Corp., St. Paul, MN, and New England 
Nuclear Corp., Dupont, Boston, MA). Reference arterial samples were obtained using a Sage Instruments model 351 withdrawal pump (Orion Research Inc., Boston, MA) at a speed of $1.5 \mathrm{~mL} /$ min over $1 \mathrm{~min}$ and $10 \mathrm{~s}$. At the end of the experimental protocol, the animals were killed by intracardiac infusion of sodium pentobarbital (Nembutal, Abbott Laboratories, North Chicago, IL). The brain was extracted immediately, and areas were separated for isotope counting. Sections from medulla, pons, midbrain, cerebellum, thalamus, white matter, and cortex were weighed, placed into scintillation tubes, and counted after correction for cross-channel spillover by a Compugamma 1282 gamma counter (Wallac; Pharmacia LKB Biotechnology, Inc., Gaithersburg, $\mathrm{MD})$. Flow values were calculated by the following equation:

$$
\begin{aligned}
& \mathrm{CBF}\left(\mathrm{mL} \cdot \mathrm{min}^{-1} \cdot 100 \mathrm{~g}^{-1}\right)= \\
& \frac{\text { counts } \cdot \mathrm{min}^{-1} \cdot 100 \mathrm{~g}^{-1} \text { of brain } \cdot \text { reference withdrawal rate }}{\text { counts } \cdot \mathrm{min}^{-1} \text { in reference blood }}
\end{aligned}
$$

Total CBF values were calculated using total brain weights and total brain counts.

Experimental design. CBF was determined during SS, $30 \mathrm{~min}$ after PhS (Phenobarbital, Goldline Co., Ft. Lauderdale, FL) infusion (PhS-treated group) or saline infusion (controls), and twice during graded hypotension. The first SS CBF and second $\mathrm{CBF}$ were determined at normal MABP. Arterial blood gases (0.4-mL samples, Corning $170 \mathrm{pH} /$ Blood Gas Analyzer, Corning Inc., Medfield, MA), Hb (BMS Cynox-1 Digital Hemoglobinometer, Cynox Corp., Clearwater, FL), and hematocrit were determined at each blood flow quantitation. $\mathrm{PhS}$ was infused at a dose of $20 \mathrm{mg} / \mathrm{kg}$ over $5 \mathrm{~min}$ intraarterially immediately after the SS CBF determination. Serum levels of PhS were obtained $30 \mathrm{~min}$ after its administration; because the drug was administered just after the first microsphere infusion, serum levels were obtained just before the second microsphere infusion. The same volume was infused and withdrawn in control animals. The amount of blood withdrawn for each reference sample was reinfused using lightly heparinized sibling donor blood after each CBF determination in both groups. After the second CBF determination, blood was withdrawn into a heparinized reservoir system for the induction of hemorrhagic hypotension. The third and fourth blood flow determinations were done at two stable successive hypotensive phases, each of which lasted $20 \mathrm{~min}$.

Analysis of PhS concentrations in serum. The serum concentration of PhS were measured 30 min after administration of the drug using an enzyme immunoassay (EMIT, SYVA, Palo Alto, CA) by the Texas Children's Hospital Chemistry Laboratories.

Statistical analyses. Analysis of the within-group variations in physiologic parameters and flow values at each treatment time was made using analysis of variance and Bonferroni $t$ tests when necessary. Analysis of between-group differences at each treatment time was performed using unpaired $t$ tests. The data were further analyzed using the BMDP5V programs (Biomedical Data Program, 5V) for unbalanced repeated-measures designs. This program was used because it allows for the presence of missing data in a repeated-measures experiment and allows for deviations from the standard repeated-measures variance assumptions. Both within- and between-group comparisons were made with this method. To examine the relationship of CBF to blood pressure, the method of LOWESS smoothing was used to generate separate curves for the treated piglets and controls (14). Based on these curves, separate regressions were performed using the random effects model for longitudinal data as developed by Laid and Ware (15). The possibility that the slope of the regression changed at $37 \mathrm{~mm} \mathrm{Hg}$ was tested using this method.

\section{RESULTS}

Physiologic data (MABP, $\mathrm{pH}, \mathrm{PO}_{2}, \mathrm{PCO}_{2}$, and $\mathrm{Hb}$ ) for $\mathrm{PhS}$ treated and control animals are presented in Table 1 . No animals were hypoxic, and there were no significant changes in $\mathrm{O}_{2}$ or
$\mathrm{CO}_{2}$ tensions within or between the two groups. MABP at 30 min after infusion of $\mathrm{PhS}$ or saline was not significantly different from SS in either group. MABP was significantly decreased during hypotension compared with SS in both groups $(p<0.01)$. MABP of the two groups during each of the four CBF determinations did not show significant differences. $\mathrm{PhS}$ serum concentrations were $1016 \pm 172 \mu \mathrm{mol} / \mathrm{L}(23.6 \pm 4 \mu \mathrm{g} / \mathrm{mL})$ in the treated animals.

The sequential changes of CBF in both groups are presented in Figure 1. CBF during the four measurements were $58 \pm 13$, $57 \pm 13,47 \pm 12$, and $29 \pm 12 \mathrm{~mL} \cdot \mathrm{min}^{-1} \cdot 100 \mathrm{~g}^{-1}$ in controls, and $54 \pm 15,47 \pm 12,37 \pm 11$, and $36 \pm 14 \mathrm{~mL} \cdot \mathrm{min}^{-1} \cdot 100$ $\mathrm{g}^{-1}$ in the PhS-treated group. There were no significant differences in CBF between the two groups during SS, 30 min after $\mathrm{PhS}$ or saline infusion (controls), and hypotension 2; however, the $\mathrm{CBF}$ in controls was significantly higher than that of the $\mathrm{PhS}$ treated group during hypotension $1(p=0.044)$.

In the $\mathrm{PhS}$-treated group, significant $\mathrm{CBF}$ decreases compared with SS were observed during hypotension at MABP of $39 \pm 6$ $\mathrm{mm} \mathrm{Hg}(p<0.01)$ and $29 \pm 6 \mathrm{~mm} \mathrm{Hg}(p<0.01)$. In contrast, in controls, CBF did not differ significantly from SS during hypotension at a MABP of $41 \pm 5 \mathrm{~mm} \mathrm{Hg}$, and only decreased significantly at $31 \pm 4 \mathrm{~mm} \mathrm{Hg}(p<0.01)$. These results were confirmed using BMDP5V. Analysis of regional CBF demonstrated that decreases occurred in all regions during moderate hypotension in the PhS-treated group, but decreases occurred only in the white matter and cerebral cortex in the controls during the first hypotensive phase (Fig. 2).

Results of statistical analysis. Using the BMDP5V program, the $\mathrm{PhS}$ (treated) and control (untreated) groups were compared. As the presence of missing data are allowed by this method, all animals contributed to the analysis. It was found that for both blood pressure and CBF there was evidence that the correlation among the treatment periods was neither constant nor patterned, so the unstructured covariance matrices were used in the analysis. The models fit were in the "classic" repeated measures form, with a treatment period effect, treatment effect, and period by treatment interactions. Significant period effects indicate that the quantity being measured changes with time; significant treatment effects indicate differences in the groups overall, and significant period by treatment interactions indicate that the two groups do not respond in the same way at each of the treatment times in which measurements are made. For the blood pressure measurements, the period effect was extremely significant, with a $\chi^{2}$ of 144.65 ( $3 \mathrm{df}, p<0.001)$. This reflects the substantial changes in blood pressure introduced at hypotension 1 and hypotension 2 in both groups. For the $\mathrm{CBF}$ measurements, the treatment period (time) effect was found to be extremely significant, with a $\chi^{2}$ of 56.37 ( $3 d f, p<0.001$ ); and the $\chi^{2}$ for the period by treatment interaction was significant at the $p<0.022$ level, with a value of $9.61(3 d f)$.

The LOWESS lines indicated that the CBF was fairly constant across all the observed blood pressures in the PhS-treated group but that it fell rather sharply in the control group for pressures less than $37 \mathrm{~mm} \mathrm{Hg}$ (Fig. 3). Using the random effects method for longitudinal data, a regression line was fit in the control animals only for the data at blood pressures less than $37 \mathrm{~mm} \mathrm{Hg}$ and one for data at blood pressures greater than $37 \mathrm{~mm} \mathrm{Hg}$. No statistically significant difference in the slopes was found $\left(\chi^{2}=\right.$ $1.76,1 d f, p<0.185)$. In a separate analysis, using both control and treated animals, and fitting one line for the range of blood pressure data for each group, a nearly significant interaction of blood pressure and treatment group was found $(p<0.088)$, with the difference indicating lower $\mathrm{CBF}$ at the lower blood pressures in the control group.

\section{DISCUSSION}

$\mathrm{PhS}$ has been used in anticonvulsant concentrations in some nurseries in attempts to prevent PIVH and has also been the 
Table 1. Physiologic variables*

\begin{tabular}{lcccc}
\hline & SS & $30 \mathrm{~min}$ & Hypo 1 & Hypo 2 \\
\hline Controls $(n=12)$ & & & & \\
$\mathrm{MABP}(\mathrm{mm} \mathrm{Hg})$ & $61 \pm 13$ & $65 \pm 14$ & $41 \pm 5 \dagger$ & $31 \pm 4 \dagger$ \\
$\mathrm{PCO}_{2}(\mathrm{kPa})$ & $4.5 \pm 0.3$ & $4.5 \pm 0.03$ & $4.9 \pm 0.8$ & $4.4 \pm 0.5$ \\
$\mathrm{PO}_{2}(\mathrm{kPa})$ & $12.4 \pm 3.2$ & $11.7 \pm 3.1$ & $10.3 \pm 2.4$ & $11.7 \pm 4.0$ \\
$\mathrm{pH}$ & $7.44 \pm 0.07$ & $7.44 \pm 0.07$ & $7.46 \pm 0.05$ & $7.41 \pm 0.05$ \\
$\mathrm{Hb}(\mathrm{g} / \mathrm{L})$ & $91 \pm 17$ & $93 \pm 16$ & $88 \pm 21$ & $84 \pm 18$ \\
$\mathrm{PhS}-\mathrm{treated}(n=12)$ & $57 \pm 13$ & $53 \pm 20$ & $39 \pm 6 \dagger$ & $29 \pm 6 \dagger$ \\
$\mathrm{MABP}(\mathrm{mm} \mathrm{Hg})$ & $4.5 \pm 0.3$ & $4.7 \pm 0.3$ & $4.7 \pm 0.5$ & $4.4 \pm 0.4$ \\
$\mathrm{PCO}_{2}(\mathrm{kPa})$ & $13.7 \pm 1.9$ & $12.7 \pm 2.7$ & $11.2 \pm 2.0$ & $11.3 \pm 2.5$ \\
$\mathrm{PO}(\mathrm{kPa})$ & $7.43 \pm 0.07$ & $7.41 \pm 0.06$ & $7.43 \pm 0.07$ & $7.43 \pm 0.08$ \\
$\mathrm{pH}$ & $88 \pm 19$ & $87 \pm 12$ & $89 \pm 18$ & $88 \pm 19$ \\
$\mathrm{Hb}(\mathrm{g} / \mathrm{L})$ & & & \\
\hline
\end{tabular}

* All values are means \pm SD. $30 \mathrm{~min}, 30 \mathrm{~min}$ after $\mathrm{PhS}$ or saline infusion; hypo 1, first hypotensive phase; hypo 2 , second hypotensive phase.

$\uparrow p<0.01$ compared with SS value.

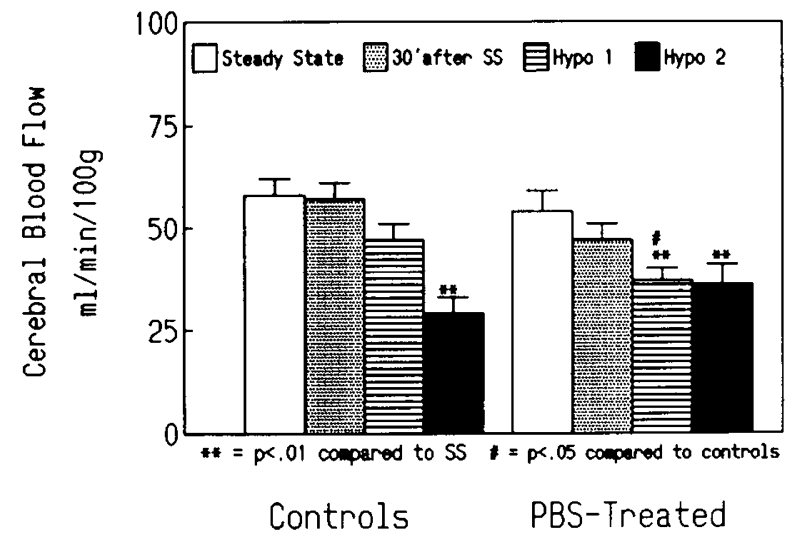

Fig. 1. Total $\mathrm{CBF}$ in controls and PhS-treated animals. All values are $\pm \mathrm{SD} .30^{\prime}$ after $S S, 30 \mathrm{~min}$ after SS; hypo 1, first hypotensive phase; hypo 2 , second hypotensive phase.

drug of choice in the treatment of neonatal seizures. However, its routine use in the first postnatal week in premature infants raises the question of potential risks related to $\mathrm{PhS}$-induced hypotension and/or the possibility of reduction of blood flow to the immature brain. PIVH is rarely an isolated abnormality in the premature infant brain. As many as $92 \%$ of premature infants with PIVH at autopsy have been reported to have ischemic lesions as well (16), and, in the clinical situation, hypotension may occur frequently in premature newborns. Although the pathophysiology of brain ischemia that occurs with PIVH is unclear at present and may be multifactorial (including secondary mechanisms triggered by the hemorrhage itself), we feel that we should be certain that physician-initiated pharmacologic interventions do not make ischemia worse. Thus, our study was designed to test the effect of $\mathrm{PhS}$ on $\mathrm{CBF}$ during hypotension in newborn pigs.

Our results showed that significant CBF decreases compared with SS were observed during hypotension at MABP of $39 \pm 6$ $\mathrm{mm} \mathrm{Hg}$ and $29 \pm 6 \mathrm{~mm} \mathrm{Hg}$ in the PhS-treated piglets. However, $\mathrm{CBF}$ were unchanged during hypotension at MABP of $41 \pm 5$ $\mathrm{mm} \mathrm{Hg}$ and only decreased significantly at MABP of $31 \pm 4$ $\mathrm{mm} \mathrm{Hg}$ in controls. The reduction of CBF due to anticonvulsant levels of $\mathrm{PhS}$ has been reported previously in hypertensive newborn beagles (11) and in newborn pigs with seizures (17). PhS has also attenuated CBF during hypertension in newborn piglets, and that effect has persisted during $5 \mathrm{~min}$ of hypoxia without hypercapnia (12).

Our analyses indicate that whereas the manipulation to lower blood pressure produced significant changes, these changes were
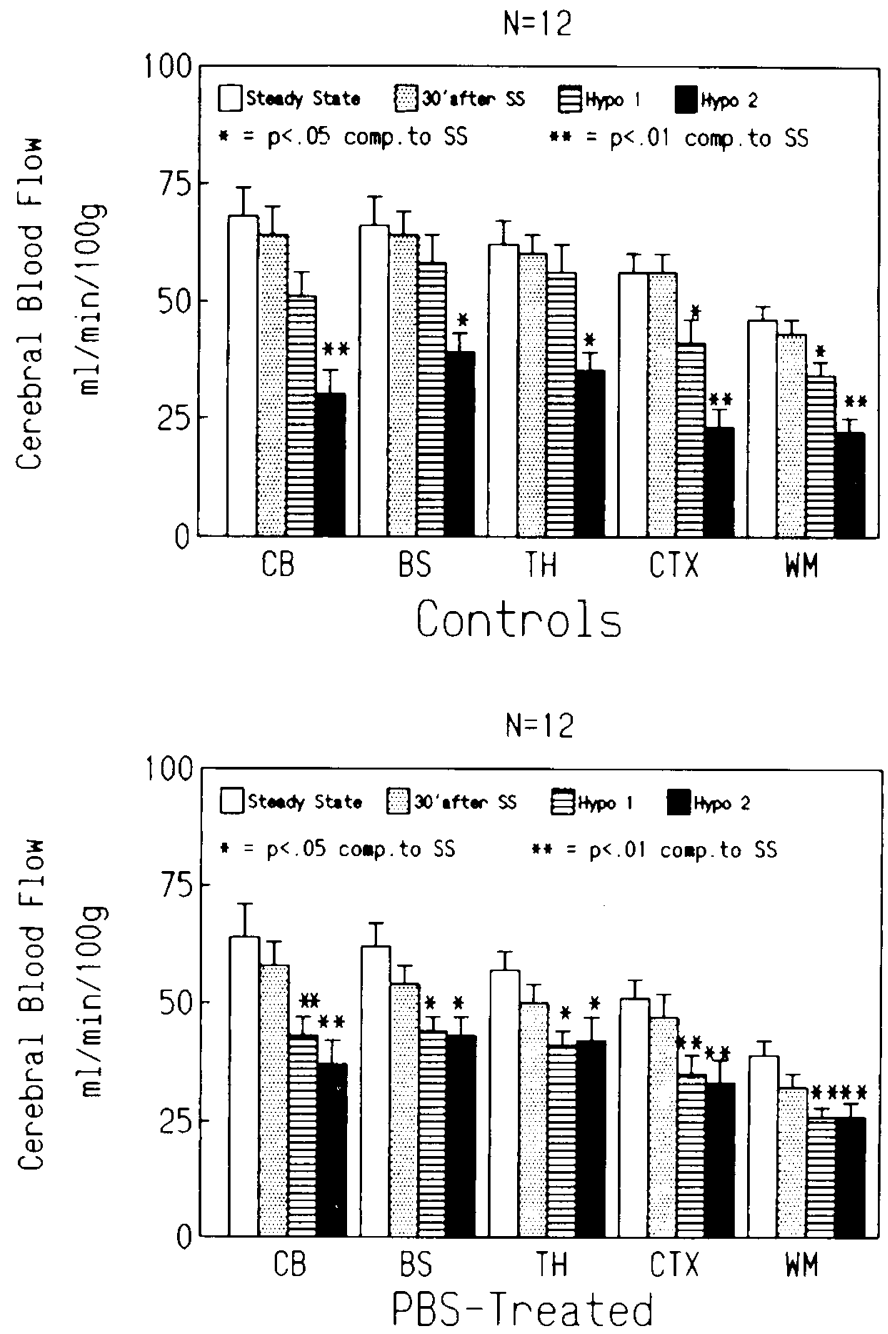

Fig. 2. Regional $\mathrm{CBF}$ in controls and $\mathrm{PhS}$-treated animals. All values are $\pm \mathrm{SD}$. $30^{\prime}$ after SS, $30 \mathrm{~min}$ after SS; hypo l, first hypotensive phase; hypo 2, second hypotensive phase; $C B$, cerebellum; $B S$, brainstem; $T H$, thalamus; $C T X$, cortex; $W M$, white matter.

not different between the two groups. Although CBF changed compared with baseline in both the $\mathrm{PhS}$-treated and control animals, there was no overall difference between the CBF in the treated and control animals until the final treatment period, during which the CBF in the treated animals was higher than 


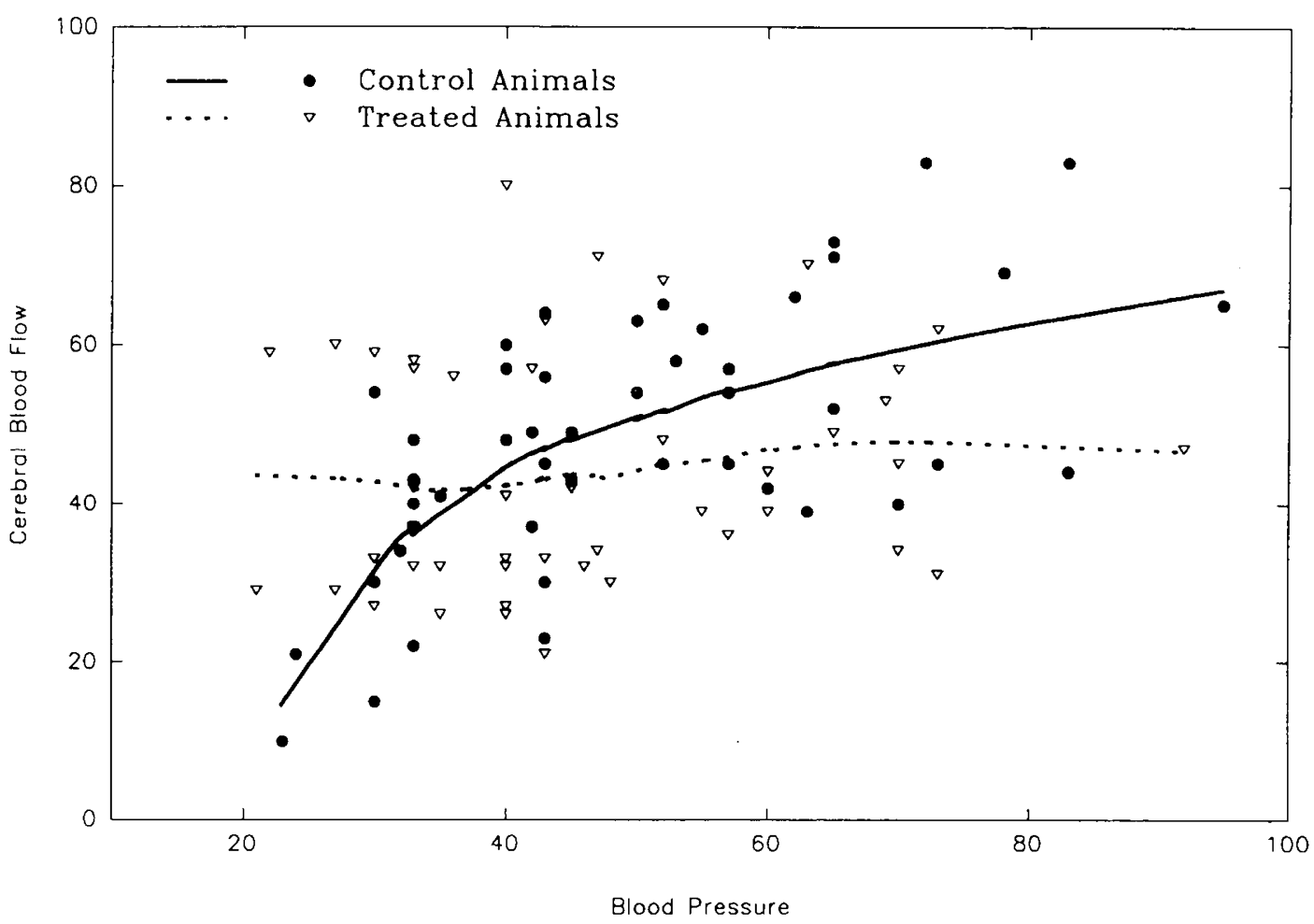

Fig. 3. LOWESS lines for CBF in PhS-treated $(\nabla)$ and control $(\bullet)$ piglets. The data intersect clearly at the blood pressure of $37 \mathrm{~mm} \mathrm{Hg}$.

that in the controls. This difference is supported by the significant interaction of period with treatment from the BMDP5V analysis.

Analysis of the current data suggests that CBF began to fall when the MABP fell below $37 \mathrm{~mm} \mathrm{Hg}$ in the control group and that, whereas the $\mathrm{CBF}$ values of the $\mathrm{PhS}$-treated group were lower than those of the controls at MABP greater than $40 \mathrm{~mm} \mathrm{Hg}$, they were actually greater than those of the controls when MABP were lower than $37 \mathrm{~mm} \mathrm{Hg}$. The lack of significance in the difference in slope above and below the $37-\mathrm{mm} \mathrm{Hg}$ value is not surprising, as only eight observations fell into this region.

These findings suggest that, rather than simply lowering $\mathrm{CBF}$ during hemorrhagic hypotension, $\mathrm{PhS}$ may lower it during modest hypotension and maintain it at that level during moderate hypotension. The mechanism of these actions has not been determined. Laudignon et al. (18) suggested in their study of newborn piglets under stress that $\mathrm{PhS}$ potentiates the vasoconstrictor effect of catecholamines. There is also evidence in newborn pigs that sympathetic nerve stimulation or administration of norepinephrine constricts pial arteries (19) and that sympathetic nerve stimulation reduces CBF (20). Other hypotheses include a direct action of $\mathrm{PhS}$ on vascular smooth muscle (21), a decrease in metabolic rate (thus producing a decrease in $\mathrm{CO}_{2}$ production and $\mathrm{H}^{+}$content in the perivascular space, leading to a reduction of vasodilatation) (17) or an effect on intracellular movement of calcium ions in vascular smooth muscle (22).

These possible explanations do not give insight into the action of $\mathrm{PhS}$ during hypotension, however. The prostanoid synthesis inhibitor, ibuprofen, has been shown to widen the autoregulatory range of newborn piglets during hypotension and hypertension and, yet, not to lower resting CBF (23). Ibuprofen's widening of the autoregulatory range has been associated with significant decreases in concentrations of PGE and $\mathrm{PGF}_{2 \mathrm{a}}$ in arterial and sagittal sinus blood and with virtually undetectable $\mathrm{TXB}_{2}$ in sagittal sinus blood in piglets during both hypotension and hypertenion. However, in vehicle-treated control piglets, PGE increased dramatically during both hypotension and hypertension, and $\mathrm{PGF}_{2 \mathrm{a}}, 6-\mathrm{keto}-\mathrm{PGF}_{1 \mathrm{a}}$, and $\mathrm{TXB}_{2}$ increased significantly only during hypotension (23). The authors' hypothesis was that the TX concentrations may play an important role in setting the lower limit of autoregulation, whereas the PGE, PGF, and PGI concentrations might play a role in setting the upper limit of autoregulation. The interactions of $\mathrm{PhS}, \mathrm{TX}$, and PG have not been determined in the newborn piglet, however, and certainly should be questions for further study.

In summary, $\mathrm{PhS}$ in anticonvulsant concentrations reduced $\mathrm{CBF}$ during modest hypotension (blood pressure $>37 \mathrm{~mm} \mathrm{Hg}$ ) but seemed to allow CBF to be maintained at lower blood pressures (blood pressure $<37 \mathrm{~mm} \mathrm{Hg}>22 \mathrm{~mm} \mathrm{Hg}$ ). Although this finding should be further corroborated, it suggests that PhS does not by itself cause ischemia at blood pressures near the lower limit of autoregulation.

\section{REFERENCES}

1. Donn SM, Roloff DW, Goldstein GW 1981 Prevention of intraventricular haemorrhage in preterm infants by phenobarbitone. Lancet 2:215-217

2. Bedard MP, Shankaran S, Slovis TL, Pantoja A, Dayal B, Poland RL 1984 Effect of prophylactic phenobarbital on intraventricular hemorrhage in highrisk infants. Pediatrics 73:435-439

3. Shankaran S, Cepeda EE, Ilagan N, Mariona F, Hassan M, Bhatia R, Ostrea E, Bedard MP, Poland RL 1986 Antenatal phenobarbital for the prevention of neonatal intracerebral hemorrhage. Am J Obstet Gynecol 154:53-57

4. Morales WJ, Koerten J 1986 Prevention of intraventricular hemorrhage in very low birth weight infants by maternally administered phenobarbital. Obstet Gynecol 68:295-299

5. Kaempf JW, Porreco R, Molina R, Hale K, Pantoja AF, Rosenberg AA 1990 Antenatal phenobarbital for the prevention of periventricular and intraventricular hemorrhage: a double-blind, randomized, placebo-controlled multihospital trial. J Pediatr 117:933-938

6. Morgan MEI, Massey RF, Cooke RWI 1982 Does phenobarbital prevent periventricular hemorrhage in very low-birth-weight babies: a controlled trial. Pediatrics 70:186-189

7. Hope PL, Stewart AL, Thorburn RJ, Whitehead MD, Reynolds EOR 1982 Failure of phenobarbitone to prevent intraventricular haemorrhage in small preterm infants. Lancet 1:444-445

8. Whitelaw A, Placzek M, Dubowitz L, Lary S, Levene M 1983 Phenobarbitone for prevention of periventricular haemorrhage in very low birth weight infants. Lancet 2:1168-1170 
9. Kuban KC, Leviton A, Krishnamoorthy KS, Brown ER, Teele RL, Baglivo JA, Sullivan KF, Huff KR, White S, Cleveland RH, Allred EN, Spritzer KL, Skouteli HN, Cayea P, Epstein MF 1986 Neonatal intracranial hemorrhage and phenobarbital. Pediatrics 77:443-450

10. Anwar M, Kadam S, Hiatt OM, Hegyi T 1986 Phenobarbitone prophylaxis of intraventricular haemorrhage. Arch Dis Child 61:196-197

11. Goddard-Finegold J, Donley DK, Adham BI, Michael LH 1990 Phenobarbital and cerebral blood flow during hypertension in the newborn beagle. Pediatrics 86:501-508

12. Goddard-Finegold $\mathbf{J}$, Michael LH 1990 Vasoactive effects of phenobarbital during hypertension and hypoxia in newborn pigs. Ann Neurol 28:450-451

13. Goddard-Finegold J, Armstrong DL 1987 Reduction in incidence of periventricular, intraventricular hemorrhages in hypertensive newborn beagles pretreated with phenobarbital. Pediatrics 79:901-906

14. Cleveland WS 1979 Robust locally weighted regression and smoothing scatterplots. J Am Stat Assoc 77:829-836

15. Laird NM, Ware JH 1982 Random-effects models for longitudinal data. Biometrics 38:963-974

16. Armstrong DL, Sauls CD, Goddard-Finegold J 1987 Neuropathologic findings in short-term survivors of intraventricular hemorrhage. Am J Dis Child 141:617-621

17. Monin P, Hascoet JM, Vert P 1989 Autoregulation of cerebral blood flow: effect of phenobarbital and pancuronium in the newborn piglet. Dev Phar macol Ther 13:120-128

18. Laudignon N, Chemtob S, Beharry K, Rex J, Aranda JV 1986 Effect of phenobarbital on cerebral blood flow in the newborn piglet under stress. Biol Neonate 50:288-296

19. Busija DW, Leffler CW, Wagerle LC 1985 Responses of newborn pig pial arteries to sympathetic nervous stimulation and exogenous norepinephrine. Pediatr Res 19:1210-1214

20. Wagerle LC, Kumar SP, Delivoria-Papadopoulous M 1986 Effect of sympathetic nerve stimulation on cerebral blood flow in newborn piglets. Pediatr Res 20:131-135

21. Edney SM, Downes H 1975 Contractor effect of barbiturates on smooth muscle. Arch Int Pharmacodynamics 217:180-196

22. Tsuji T, Chiba S 1987 Mechanism of vascular responsiveness to barbiturates in isolated and perfused canine basilar arteries. Neurosurgery 21:161-166

23. Chemtob S, Beharry K, Rex J, Varma DR, Aranda JV 1990 Prostanoids determine the range of cerebral blood flow autoregulation in newborn piglets. Stroke 21:777-784 